\title{
'WE ARE NOT ACCEPTED HERE'
}

\author{
Intersecting vulnerabilities of internally \\ displaced adolescents in Ethiopia
}

\author{
Nicola Jones, Kate Pincock and Workneh Yadete
}

\section{Introduction}

The 2030 Agenda for Sustainable Development pledge to 'leave no one behind' offers a key opportunity to build on existing efforts to address internal displacement. The Internal Displacement Monitoring Centre (IDMC) defines internal displacement as the involuntary flight of people from their places of habitual residence, within the borders of their own countries, 'as a result of or in order to avoid the effects of armed conflict, situations of generalized violence, violations of human rights or natural or human-made disasters' (United Nations Office for the Coordination of Humanitarian Affairs (UN OCHA), 1998). The 2030 Agenda specifies internally displaced persons (IDPs) as a vulnerable group that must be empowered through efforts to achieve the Sustainable Development Goals (SDGs) (de Barre et al., 2018). In 2019, UNICEF estimated that 19 million children and adolescents were displaced within their own country - the highest number ever recorded (UNICEF, 2020).

Displacement disrupts transitions to adulthood in multiple ways.Adolescence is a key life stage that brings unique physiological, emotional and social changes which see young people becoming more involved in their communities and making decisions about their futures (Punch, 2002; Del Franco, 2012). Yet displacement breaks down adolescents' social networks and communities; it restricts their opportunities for education, work and agency; and it increases their exposure to violence and subsequent poor psychosocial outcomes (Guerrero and Tinkler, 2010). However, unlike refugees, there are few actors mandated to support IDPs beyond the initial emergency response (Lanz, 2008; Landau, 2014). IDPs also tend to be marginalised within national development strategies, which are ill-suited to coping with mobile and temporary populations and their particular vulnerabilities (Habte and Kweon, 2018). Policy responses that do engage with IDPs tend to either overlook 
the gendered vulnerabilities of young people or simplify them, treating adolescent boys as potential threats and girls as passive victims of sexualised violence (ClarkKazak, 2009; Cazabat, 2019).

The 2030 Sustainable Development Agenda and the Global Compact on Refugees have called for humanitarian efforts to better connect with national development actors, creating a 'humanitarian-development nexus' that includes displaced people in development planning (Turk, 2018). Yet internally displaced adolescents are at risk of 'falling through the cracks' of this nexus because of a lack of meaningful state and international attention to the specific challenges of internal displacement within these frameworks (Evans et al., 2013), including an absence of any indicators on IDPs in the 2030 Agenda (Nahmias and Krynsky Baal, 2019). Reflecting the 2030 Agenda's urgent call to 'leave no one behind', this chapter seeks to address these knowledge gaps, exploring intersecting disadvantages faced by internally displaced adolescents in Ethiopia in Dire Dawa City Administration (Somali IDPs) and in East Hararghe and East Shewa zones (Oromo IDPs). Focusing on economic and psychosocial vulnerabilities, we highlight variations in experience based on IDP age, gender and geographical location. At a structural level, these vulnerabilities are amplified by governance failures, underlining the need for sustained and coordinated support for IDPs beyond the initial emergency phase.

\section{Background}

\section{Internal displacement in Ethiopia}

Mass internal displacement due to flooding, fires, drought and conflict has been a recurrent risk in Ethiopia for several decades (de Brauw and Mueller, 2012). In recent years, climate variability in the Horn of Africa has been described as a direct catalyst for violence, with resource scarcity as a result of droughts and flooding magnifying tensions that already exist as a result of structural inequalities and government instability (Afifi et al., 2012). In the second half of 2017, hundreds of thousands of Ethiopians were driven from their homes by border disputes between the Oromia and Somali regions, which share a border of 870 miles. By the end of 2018, 2.9 million people had fled their homes. At the same time, rapid political change was occurring in the country, reflecting calls for greater democratic freedoms and an end to the ethnic-based governance structure that was perceived to have marginalised many ethnic groups politically and economically. In early 2018, the newly created Ministry of Peace (replacing the Ministry of Federal Affairs, which had been criticised for inadequate support to displaced people) began to play a key role in supporting IDPs, helping an eventual 1.8 million return to their home communities (International Organization for Migration (IOM), 2019).

However, continued displacements due to upsurges in conflict along border regions and disasters such as flooding have tested the new ministry's capacity. Ongoing internal displacement has not only fractured families and communities 
but also increased exposure to violence (during displacement and afterwards, with significant impacts on people's physical and mental health and wellbeing) and driven widespread hardship and poverty due to the lack of economic opportunities for IDPs (Yigzaw and Abitew, 2019). For many IDPs, returning to their homes and recommencing normal life is impossible; their homes and businesses were destroyed, there is little or no support for rebuilding, and ongoing insecurity has led to high rates of secondary displacement (OCHA, 2019a). There is no alignment between federal and regional policy and budget allocations and responsibilities; for example, when conflict broke out in late 2017 between Oromo and Somali communities along regional borders, the Oromia regional government had to intervene owing to the slow response of the federal government to stem the violence.

Displaced Oromos and Somalis sought refuge in camps and host communities around the border areas. Oromia has some of the highest rates of IDPs in the country; according to the IOM, East Hararghe zone alone was hosting nearly 150,000 IDPs across 165 sites (IOM, 2019), mostly Oromos who had fled Somali region. When violence first broke out along the border in late 2017, many families who fled were unable to find safe places to stay, but as their numbers increased throughout 2018, the government and international humanitarian community were forced to respond, establishing shelters for families on the move (Sida, 2019). In Dire Dawa city, a large IDP camp was established at Millennium Park, mostly home to Somalis who fled the fighting in Oromia. Overcrowded shelters with limited food, health, nutrition, sanitation, education and protection services have exacerbated the vulnerability of IDPs in camps (Sida, 2019), yet those outside camps are also vulnerable, with lack of assistance and ongoing insecurity causing secondary displacement (IDMC, 2018, 2020).

\section{Challenges for humanitarian assistance in ensuring an inclusive IDP response}

While the Office for the Coordination of Humanitarian Affairs (OCHA) and other humanitarian organisations have looked at the impact of internal conflict on food aid, education, health and nutrition in Ethiopia, none have considered how displacement has affected adolescents specifically (OCHA, 2019a, 2019b). Existing evidence from previous crises, as well as work with IDPs in other contexts, points to the significant economic and psychosocial impacts of forced displacement (Siriwardhana and Stewart, 2013), especially for already-vulnerable populations such as young people and women (Araya et al., 2007; Betancourt and Khan, 2008). Yet IDPs in general, and young IDPs specifically, remain a low priority for international humanitarian assistance in comparison to other forcibly displaced populations (Buscher and Makinson, 2006). In part this is because the Guiding Principles on Internal Displacement assert that states are responsible for addressing the rights of internally displaced persons (OCHA, 1998; Cotroneo, 2018) - a stance which assumes that governments are able to protect IDPs (Brookings-LSE, 2014). 
The Ethiopian government is developing strategies to address internal displacement. In February 2020 it ratified the 2009 African Union Convention for the Protection and Assistance of IDPs in Africa (the Kampala Convention) and has worked with partners (including the UN) to develop its 2019 Humanitarian Response Plan. Yet policies continue to overlook the specific vulnerabilities of younger people, despite wide acknowledgement that during conflict, women and children tend to bear the brunt of violence. For example, the 2019 Humanitarian Response Plan makes only one mention of 'children and adolescents' - specifically, the vulnerability of out-of-school children to child labour and trafficking (Government of Ethiopia, 2019: 83). In terms of interventions, the Plan refers to adolescent girls and boys as 'engaging in risky behaviours and negative coping mechanisms' (ibid.:17) and in need of interventions which tackle this. However, proposed response strategies focus on girls (usually grouped in with 'women'). These include: sexual and reproductive health (SRH) interventions targeting the needs of children and adolescents as well as people with disabilities, women and people living with HIV and tuberculosis (ibid.:45); recognising the particular protection needs of adolescent girls (ibid.:55); dignity kits and awareness raising among adolescent girls (ibid.:56); and psychosocial support for adolescent girls through women-friendly spaces (ibid.:57).

Similarly, the UN OCHA, outlining funding priorities for the response to mass internal displacement in Ethiopia, defines several urgent issues in which girls are the primary focus, although adolescent girls are addressed within gendered strategies for women. OCHA identifies the need for psychosocial support for children but specifies that 'women and adolescent girls will be given psychosocial support in women-friendly spaces' (OCHA, 2019b: 4); it goes on to talk about engaging caregivers in promoting child wellbeing, implying that the women and girls in this context will be mothers of traumatised children who may also need support. Women and adolescent girls are also to be trained in awareness and mitigation of gender-based violence (GBV), with services expanded to support victims (2019b: $5)$. There is, however, little attention to how gendered needs vary across and within age groups and life stages (Evans et al., 2013).

There is a growing evidence base that the vulnerabilities of adolescents in Ethiopia are shaped not only by gender norms but by other differences too, including geographical location (Jones et al., 2020) and household food security (Jebena et al., 2016). GAGE quantitative research in Ethiopia has found that children in rural areas are more likely to have experienced violence than those in urban contexts (67 per cent vs. 59 per cent) because of community support for norms that permit violence against young people (Murphy et al., 2020). Jebena et al. (2016) employ a structural equation model to identify strong links between poverty, food security and poor mental health amongst Ethiopian adolescents. Given that household incomes and community networks are both altered by internal displacement, these quantitative findings underline the need for context-specific approaches to promoting economic opportunities and psychosocial wellbeing which take into account the ways these may be fractured by displacement. 
The United Nations High Commissioner for Refugees's (UNHCR) reference to 'children and adolescents' in its Age, Gender and Diversity (AGD) policy suggests recognition of the different developmental and social circumstances of young people. Yet there is a lack of consistency in how definitions are applied within policy literature and a lack of nuance in discussions (Clark-Kazak, 2009). This is exacerbated by a dearth of age-disaggregated data; the AGD policy states that children and adolescents should be supported to participate 'in all matters affecting them in accordance with their age, gender, maturity and capacity' (UNHCR, 2018: 18) but does not require that data be disaggregated beyond 'adults' and 'children', rendering it difficult to identify what support might be needed for different cohorts.

The United Nations' Global Compact on Refugees (2018) seeks to bridge the aid-development nexus to find ways to promote long-term solutions to displacement; yet it does not include targets for promoting self-reliance for displaced people and supporting peacebuilding in communities of origin so that IDPs can return safely. The need to address climate change as part of strategies to reconcile conflicts over resources in the region is also overlooked. The 2030 Agenda, and the call to leave no one behind specifically, addresses groups that are structurally marginalised and draws attention to the vulnerability of IDPs and the need for their empowerment (UN, 2015). Yet while the Agenda document was recently updated to add an indicator on displacement, it will be based on UNHCR data and thus only includes refugees (Nahmias and Krynsky Baal, 2019). There will be no data on how IDPs are faring in comparison to other displaced population groups, which presents a major obstacle to ensuring that states include IDPs in development planning and policies.

\section{Conceptual framing}

Ensuring that there is adequate data on internal displacement, age and gender is an important component of assessing needs and designing appropriate interventions to 'leave no one behind'. This research unpacks the specific age- and genderrelated vulnerabilities of adolescents in two areas that have received little attention: the economic and psychosocial effects of internal displacement. In analysing how these dimensions are connected and what support adolescents need, we draw on two complementary conceptual frameworks: an intersectional approach, and the ' 3 Cs' - capabilities, contexts and change strategies - employed by the Gender and Adolescence: Global Evidence (GAGE) longitudinal research programme (GAGE consortium, 2019).

GAGE's focus on capabilities draws on Amartya Sen's work $(1984,2004)$ and reflects commitments to a holistic understanding of young people's rights and the need for investment across all areas of their lives (as enshrined in the UN Convention on the Rights of the Child). Sen's capabilities approach (2004) proposes that in order to achieve and do things that they value, individuals need assets such as knowledge, skills, bodily autonomy, health and voice. When considering at-risk young people, this means addressing how a lack of assets - for example, access to schooling or health care - prevents them from achieving their capabilities, while 
focusing interventions on these areas of capability deprivation. Being displaced, being of a certain age and being a particular gender or ethnicity can make young people particularly vulnerable to capability deprivations. Drawing on the work of Crenshaw (1989) on intersectionality, we suggest that these 'intersections' of personal identity are critical to how internally displaced adolescents (especially girls) experience vulnerability. Approaches that engage with vectors of inequality such as gender, displacement, rural-urban divides and age as distinct rather than related issues will fail to address both the specifics of these experiences and the systemic nature of inequalities in reproducing and reinforcing each other (Collins, 1990; Nash, 2017).

Building on this recognition within intersectionality that vulnerability is a product of unjust social systems, the GAGE conceptual framework emphasises the role of context in shaping the vulnerabilities experienced by internally displaced adolescents. Context includes not only the relationships in which young people are embedded at the household or family level; it also encompasses social norms around gender and age enacted at the community level, and the role of state and global actors, whose power to define issues and allocate resources shapes young people's economic and political opportunities.

Intersectionality theory also emphasises the role of historical context in situating groups differently along axes of power (Yuval-Davis, 2006). In the case of Ethiopia, longstanding ethnic and political tensions (including conflicts over ever-decreasing water and land) continue to shape young people's experiences of displacement. In this research, some IDPs were staying in communities still immersed in conflict, and others were in camps. These locations may also create different vulnerabilities, given that encampment both draws attention to IDPs and simultaneously makes them as different in negative ways, due to the diminished quality of life that residents have in such places (Kreichauf, 2018). As well as creating a sense of resentment and hostility from those outside these spaces who do not have to live in them, being marked as different may also exacerbate young people's sense of ostracism from society.

Finally, the GAGE conceptual framework attends to change strategies - the policies and programming needed to support young people to develop their full capabilities, which must account for the contextual realities of adolescents' lives and the intersecting vulnerabilities they generate. These broad contextual dynamics provide the backdrop to young people's experiences of and vulnerabilities to displacement, as explored in this chapter. The focus on change strategies also underlines the importance of connecting our findings to recommendations for action to address the vulnerabilities facing adolescents in Ethiopia.

\section{Methodology}

Our findings are based on research conducted in late 2017/early 2018 and late 2019 in East Hararghe's Fedis woreda (district), on the border with Somali region, and Dire Dawa City Administration and Batu town, in Oromia region's East Shewa zone. The participants were internally displaced adolescents in East Hararghe 


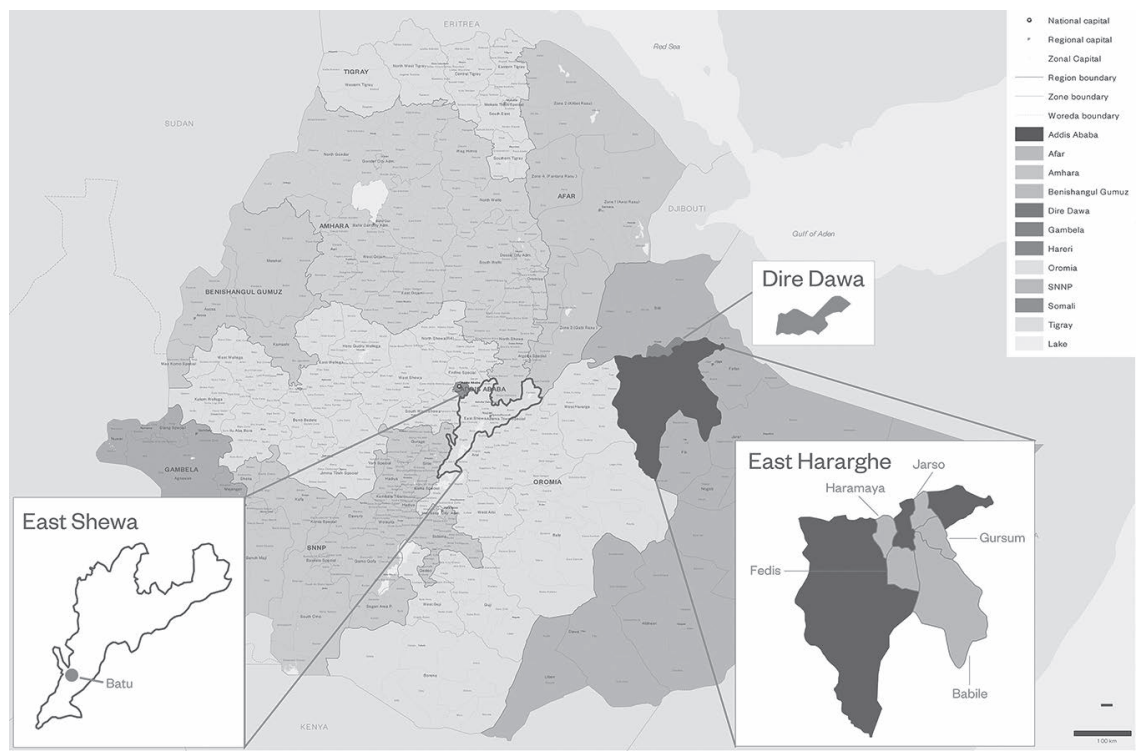

FIGURE 3.1 Map of Ethiopia indicating fieldwork localities.

(Oromos displaced from Somalia) and Dire Dawa (Somalis displaced from Oromia region, and Oromos displaced from Somali region). Figure 3.1 illustrates the locations of these field sites.

Research was undertaken in two areas with high concentrations of IDPs; however, at baseline, as GAGE was not anticipating to focus on IDPs, data was being generated as the crisis unfolded, with qualitative tools adapted to capture the emerging experiences of young people. In the second round of data collection (2019), we used the same tools to explore significant change in displaced young people's lives since the first round. This data was complemented by focus group discussions and key informant interviews to explore both the broader community dynamics, and district and regional policy and political dynamics.

Sampling was purposeful, with community leaders and facilitators requesting to introduce researchers to IDPs in their communities. Fieldwork was undertaken by local researchers who spoke the same language as respondents, and the same team undertook both rounds of data collection. Ethical challenges included the need to anonymise findings due to security concerns and (in Dire Dawa) finding safe locations for in-person interviews due to ongoing political tensions/insecurity during the second round of data collection.

IDPs in Dire Dawa city included two major groups: 3,192 Oromos who were displaced from Somali region in 2017/2018 and settled at two sites on the outskirts of the city administration, and 483 Somalis who were displaced from Oromia zones bordering with Somali region and settled in the city youth centre. ${ }^{1}$ Table 3.1 shows the mid-line interview sample of internally displaced adolescents and key informants. Though official reports indicated that IDP centres received basic services such 


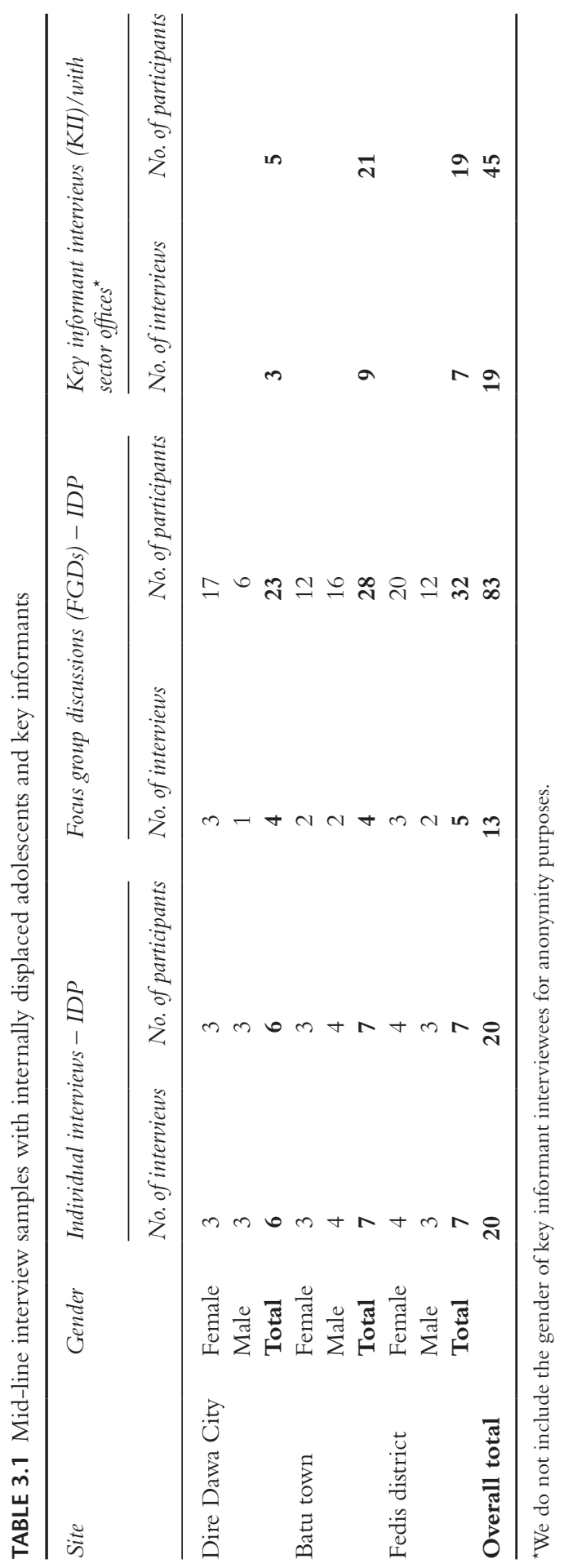


as shelter, food, water, hygiene and sanitation, and health care (IOM, 2017), our researchers observed that by late 2019 most of these services had stopped and IDPs lacked access to health care and education, water and sanitation, and social protection. There were also conflicts among different clans within the centres as well as disputes with host communities.

In Batu town in East Shewa zone of Oromia region, the IDPs were mainly displaced from the Shilile zone of Somali region in 2018. The Oromia regional government settled these IDPs in Batu in 2018 in accordance with the government's policy to settle many IDPs in large urban areas within Oromia region, based on a quota system. The IDPs in Batu have been living in two big IDP centres in Kebele 02 of the city administration. Though the government provided them with food, free health services in local hospital and education services in government schools, the displaced population strongly complained that the support has been inadequate and that they have been excluded from social, political and economic opportunities. This has led to repeated conflicts with the city administration officials, as well as with the communities living around the IDP centres. This has led to migration of many IDP young people to the Middle East through illegal means often in very risky circumstances.

In East Hararghe zone, there were 85,292 Oromos displaced from Somali region (late 2017/early 2018), with 72,861 settled in IDP centres in different woredas (or districts across East Hararghe zone). Fedis woreda (where we conducted qualitative research), a remote rural district, hosted an estimated 7,421 people displaced from Somali region (IOM, 2017), and there were large numbers of locally displaced people within the woreda due to ongoing border tensions. The total number of IDPs in East Hararghe reached 310,000 in mid-2019 (OCHA, 2019b). A significant proportion of IDPs returned to their place of origin but often lacked land or livelihoods as they had lived and worked in Somali region or elsewhere for long periods of time, and thus they were often heavily reliant on family members or neighbours, many of whom were already facing precarious livelihoods. It is important to note that East Hararghe suffers from poor infrastructure and very limited employment opportunities outside of the khat (a stimulant plant that is widely consumed in parts of Ethiopia and the Horn of Africa) economy, and hence large numbers of the rural population had moved in previous years to other regions in search of better livelihood opportunities. Post-conflict, those who are still living in rural communities in East Hararghe are dependent on the support from the government, which has been provided in a haphazard way, rendering IDPs highly vulnerable. Since the support is predominantly food items, the IDPs have lacked money to cover costs for medical, transport, clothing, additional food items and other non-food necessities. Moreover, many of them remain living in tents which exposes them to extreme temperatures during the day and night, and additional challenges during the rainy season.

\section{Findings}

As of mid-2019, Ethiopia's Ministry of Peace, with support from humanitarian organizations, had successfully relocated 1.8 million of about 3.2 million displaced 
persons (IOM, 2019). Despite this considerable achievement, our findings paint a more sobering picture of very high levels of vulnerability among internally displaced adolescents and their families, in rural and urban host communities and in IDP camps. Here, we focus on the patterning of economic and psychosocial vulnerabilities among internally displaced adolescents.

\section{Economic vulnerabilities}

Many of the internally displaced Oromos had migrated to Somali region due to poverty and limited economic opportunities in their home communities (including lack of land and other productive assets). In the case of IDPs from Somali and Oromo regions, due to the extreme violence encountered during the initial conflict, many had been forced to flee without savings or assets. When they arrived in camps or host communities they were already highly vulnerable, and two years on, many remained homeless, living in tents or make-shift shelters. Arriving in already highly impoverished communities with limited economic opportunities exacerbated the challenges facing IDPs. As an adult in a focus group discussion (FGD) for fathers in Fedis district explained:

After we arrived here, we did not get basic needs. The local community is also poor and unable to support us. My father lives here without having resources, when I came with additional problems, the challenges were compounded. Hence the government needs to help us.... Those who are displaced lost all their belongings. . . . People migrated from this locality since they did not have anything at the time they migrated. . . Those who have nothing, they are living just as they were before. When the displaced people consume what they get from the government, their relatives end up having to sell their assets so as to purchase basic consumer goods. In doing so, both of them are losing their resources and becoming poor.

Internally displaced adolescents across the research sites underscored the challenge of food insecurity. One 19-year-old girl from Batu explained that IDPs had also been reluctant to speak out initially because they were grateful for having been rescued from the brutal ethnic violence:

Our people took us out of that bad situation. That was the reason we were patient. We tell ourselves that we didn't come here for the food or belongings we get. We were afraid to talk about food. We were patient. We did that for the sake of our people and God.

Mothers in an FGD in Fedis district underscored the desperate situation that many IDP households find themselves in, especially because prior to displacement, they were already relying on their adolescent children's labour to meet basic needs. As one 35-year-old woman explained: 
Our people were working as a housemaid like cooking, washing clothes, etc. Others who have their own home were engaged in small trade of vegetables. Girls were engaged as a housemaid and earned up to 2000 birr per month. Boys were engaged in washing cars, as a shoe polisher. Such children did not need anything from their parents. However, after they came here, they do not work and we are also unable to provide them with basic needs. It is only God who knows about the sufferings that I faced.

\section{Limited employment opportunities}

Adolescents in rural areas noted that some had been compelled to engage in paid work within the host community to support their families, often on exploitative terms. One 16-year-old boy noted:

Local adolescents work on their families' farms out of choice, whereas we are becoming their servants just for the sake of earning some money. Most of us don't have our farmland; even if we do, we don't have oxen to plough the land. That is why we have become paid labourers and servants of the betteroff people. We have scant opportunity to work and improve our livelihoods.

For many meeting household economic needs was coming at the cost of school attendance. One 17-year-old boy explained: 'We sacrifice our schooling for income-generating work. We see limited future.'

Older adolescents residing in cities or towns emphasised that while they had been moved to urban centres by the government, ostensibly to facilitate access to employment, finding work had, in practice, proved very challenging, and they had not received any support in the process. As an 18-year-old internally displaced girl living in Batu noted:

[After we were displaced] we returned to our birthplace empty-handed. Our family bought us clothes and shoes, and then the government brought us here [an urban centre] . . to this ugly livelihood. Government tells us to become independent and to have an independent life. Government tells us it enables us to work. But we do not have any work. We do not have any money. We sit in line here without having anything.

Older youth participants in an FGD emphasised that they were not given equal citizenship rights after they were displaced. One 22-year-old male noted:

In this local town, all priorities are given for residents of the town. We requested to get job opportunity ... but the response was that local residents do not get such opportunity yet. We are guests for the town. This is what negatively affected our morale. ... When we asked government officials to provide us with job opportunity, they told us to wait for five years. 
Government officials informed us they are unable to support unless they first support the local residents.

Many of the Oromo adolescents who had migrated to Somali region prior to the conflict in search of work had dropped out of school early in their home areas due to household poverty, so they had limited skills and experience with which to secure new livelihood opportunities.

In other cases, internally displaced adults highlighted that the challenges young people were facing post-displacement were a result of a general de-valuation of education. As a participant in an FGD for fathers noted:

Since father and mother do not know about importance of education, such ignorance transferred to children. Our people are in ignorance and darkness. So government needs to provide strong awareness raising in the community.

A number of respondents explained that they had not attended school in Jijiga after migrating to Somali region, partly due to language barriers and stigma but also because it had not been a priority for their families.

\section{Limited social protection}

Our findings highlight that in the initial aftermath of the conflict, emergency social protection support was slow to arrive, so many households outside camp settings were reliant on support from host communities. Once support (primarily food aid) had arrived, it was for a limited duration; many respondents noted that even though their situation had not improved by late 2019, they were no longer receiving support and were living precariously. As a 19-year-old boy living in Batu noted:

Previously they were supplying us with food rations bi-monthly. Now, it has been four months since the support stopped. . . They did not give us anything. We do not have any job.... We are wearing the clothes we were wearing when we came here [displaced from Somali region]. ... They gave us 15 kilos of rice, we do not have anything to buy other needs that we have. It has been two years since we came here. We are facing severe challenges. We do not have jobs. We are not attending school. By now we are not using our time, rather, the time is running against us. But we cannot say anything.

In some cases, internally displaced adolescents reported that they were relying on peer support for basic needs. As a 19-year-old boy in Batu explained:

Those boys who work support them.... We request from them money for soap. We eat food with them if they have, if they do not have we leave it. We are living just like this. 
Adolescent girls similarly noted close cooperation with displaced peers as their only option for survival. As an 18-year-old girl living in Batu explained:

Where I live, there are 461 displaced households. There is a woman from Chelenqo and I am dependent on her for my food. When she gives me food, I take it to my friends and eat it together with them. . . . If they too get something, they bring it and share it. We use 15 birr [0.43 USD] for two days.... We are now attending school and ... if my skirt is dirty, I wear the skirt of the others.... When we came back from school, we did not have anyone who bought water for us. . . We did not get water for five days, either for drinking or for cleaning. Then I had to miss school since I did not have any water to clean myself. We had only one jerrican of water.... During that time, I cried and decided to quit school. . . Then my friends came from school and encouraged me not to quit. They advised me that hardship will pass.... It has been two months since that moment. However, there is no solution yet.

Other adolescents highlighted that many young people are forced to incur debt, while others have returned to Jijiga in Somali region, despite the risks of ongoing ethnic tensions. A 19-year-old married adolescent girl living in Batu said:

Sometimes we make do with the money they [family and neighbours] lend us. In the future when there is nothing to eat ... The situation that we are living in is greatly worrying.... Because of the absence of aid, many people are worried about how to repay the loan they took... Some are returning and working in Somali region as before. There are many who returned there because the livelihood here is so worrying and the food rations are on the verge of stopping.... I am now working and I can repay my loan.... But there are people who do not work. Yet, there are persons who do not start work after they took the loans and so can't repay the money.

Young people also noted the lack of social protection support to cover basic costs such as education for IDPs. For example, in secondary school, young people need to pay additional fees for group tutorials, but the fees are not waived for IDPs, as this 17-year-old boy living in Batu explained:

Lack of money has hampered my education greatly. Even today, there was a conflict with my group within my class. This is because my group was interested to attend the tutor class and I was the only student unable to pay for that. I requested my group members to pay 5 birr and let the school register me. But impossible.... Later I informed them to exclude me and to register other students. ... I told them I will bring the money. But they refused to register me. .. But I did not feel any anger towards them. 
Similarly, a 13-year-old displaced girl living in an IDP camp in Dire Dawa noted that she and her siblings were out of school as their family could not afford the school uniform:

When they were taking photos of our parents and were registering family, they told them to buy uniform and send children to school. But our parent $[\mathrm{s}]$ said, 'We don't have money to buy uniform'. They told them, we will send our children to school when we have money and are able to do that.

Some boys also explained that lack of money means that displaced students risk being excluded from sports classes as they cannot afford sports shoes, and the school does not have an exemption policy. As a 17-year-old boy explained:

When we practice sport activities, you may face several challenges. . . Our sports teacher gave us two months to get sport shoes. Then after, he said to us, 'I do not have the patience to let you participate in sport activities unless you wear sport shoes'. Because of this I beg shoes from other students from other classes for when they do not have sport classes. So I am participating in sport classes with shoes that I beg from others.

\section{Psychosocial vulnerabilities}

Our findings underscore the multilevel psychosocial stresses facing adolescent IDPs at the individual, family and community levels, and the dearth of psychosocial support services. Here we discuss each level in turn.

\section{Individual distress}

Many adolescents spoke of the deep initial shock they had experienced during the conflict and the effects of witnessing violence. As a 17-year-old boy from Batu explained:

I was in great shock. I did not want to eat or drink. . . No one can think about hunger unless there is peace... I have never ever been shocked like at that moment. I never faced such type of a disaster. . . It was a nightmare during the day.

Another 19-year-old boy from Batu noted:

We do not want to return there. We suffered a lot at that time, they beheaded people. . . I c counted 340 people, women whose lips were cut off. When I saw all this I was badly affected.... Therefore we have no interest to go back there.... We are frightened. 
Many young people reported that the shock and trauma had manifested itself in physical ailments, as a 12-year-old girl in Dire Dawa explained:

I became sick and later got cured. It was Allah who cured me.... I was sleeping for six months. Even after I came here, I was sick. They took me to the health facility and I was cured. I had a headache and felt ill in my abdomen. My whole physical structure felt like I had been smashed. While I was in Oromia, they were imprisoning the health workers [and so health care was difficult to obtain]. But when we came here, they took me to the health facility. Then I got cured.

Multiple respondents spoke of the injury or death of family members, which gave them ongoing nightmares. A 12-year-old girl living in a camp in Dire Dawa recalled her experience:

When my father died, deep inside I felt I will kill one of them [the perpetrators] and die there. . . I didn't sleep. For many nights I couldn't sleep. I still have nightmares. They call me 'Somali' and threaten me with a knife in my dreams. Then I wake up.

A 15-year-old boy in Dire Dawa noted:

I lost my father and mother. I am living with my grandfather. ... Our house was burned.They killed my uncle... My elder sister was sick [when we were displaced] and recovered here. My smaller sister who was five years old was also sick and died.

In addition to the psychological trauma of the initial conflict period, displaced adolescents and parents also spoke about the stresses young people are experiencing due to being out of school, and the barriers (not least cost) that prevent them returning to school. As a mother living in a Dire Dawa camp noted:

When the violence occurred, they left their exercise books in their class to save their life. They are also required to pay money to buy exercise books. They are worried about their low performance. . . Though I was trying to encourage my children to focus on their education, my husband got sick and couldn't support them and then [they] dropped [out of] school. They are so worried about their education.

Some parents also explained that their children were distressed because of their exclusion from school on account of not having the necessary paperwork to demonstrate their grade level prior to displacement. 


\section{Family support}

While emotional support from families is a key pillar of adolescent psychosocial wellbeing, many adolescents in our sample reported feeling unable or unwilling to rely on their families, as they knew how the conflict and displacement had affected them too. Older adolescents living in host communities in Batu emphasised that they did not turn to their families for economic or emotional support because they were themselves struggling and not in a position to help. As a 19-year-old boy in Batu explained:

My family does not know I am suffering here.... My father does not know about my situation here. ... I do not tell him.

Similarly, an 18-year-old girl living in Batu noted:

My family [who live in a rural village in East Hararghe zone far from Batu] cannot support me. My family are farmers. My family produces on a yearly basis and they do not have excess resources to help me. On top of this, my family is educating other children. It is difficult for us to request the family to send us money. It is difficult and shameful to request my family to send me money.

Others were afraid to return home even to visit, citing transportation costs and the risk that they could lose what limited employment they currently had. As a 17-year-old boy noted:

They do not come. But they call me several times, it is me who has become silent ... I will not return from there if I go. . . I need at least 1,000 birr just to go there and come back here. ... I stayed here since I have a job. Since those who do not have job do not move back there, why should I go while I have a job? I think over it and decided that since I have a job here. . . I I am thinking of my family. It has been almost three years since we came here.

\section{Community connectedness}

A common theme across research sites was the lack of community social cohesion. While young people spoke of support from host communities soon after they arrived, in many cases this appeared to be short-lived. Many adolescents, especially in the second round of research, spoke of social isolation or stigma from host communities. As a 19-year-old girl in Batu noted:

We don't participate in any activities [with the host community].... We do not use the youth centre. We do not know where it is. No one showed us. 
The lack of safe spaces to interact with peers was a particular concern for girls, who face tighter restrictions on their mobility due to gender norms, and also on account of trauma related to sexual and gender-based violence that many girls and young women had experienced during the conflict.

Some adolescents talked about being insulted by others in the community but felt they had little option but to tolerate this discriminatory behaviour, especially because their poverty further undermined their social standing. A participant in a girls' FGD observed:

We could do nothing except bow down our head and move away. ... We felt that it is our fate to be exposed to such bad things... . We felt that it is our poverty that caused all the discrimination against us.

Several younger adolescents (from Somali region but now living in Dire Dawa) noted they had participated in meetings where they received advice about interacting with the host community (which is ethnically mixed), including not resorting to violent behaviour with Oromo youth. For example, a 12-year-old girl explained:

They advised us.... They called us for a meeting under a tree and advised us not to attack other people. Now we don't do that anymore... They told us not to attack Oromo children. You are poor and cannot protect yourself from them. The Oromo are many in the town, you cannot stop them or protect yourselves from them. We say 'ok' but when we see Oromo around here we used to beat them. They repeatedly advise us to stop it and we did stop now. Now, the Oromo enter the compound and leave. We don't talk to them. But we don't leave them if they provoke us.

A participant in an FGD for mothers in Fedis district explained that bullying of displaced children by host community children at school was commonplace:

Sometimes children of the locality take school materials of my children. In that case, I ask the teacher to provide them [with] exercise book and pen. Local children beat our girls aged 13 or 14 years. When I appeal to the parents of such children to stop their children, no one prevents their children from beating our children. Some of the people are good while others are bad.

Several younger adolescents also emphasised that teachers were not providing support; not only were they failing to intervene to prevent conflict among students but in some cases they were allegedly encouraging mis-treatment of internally displaced students. A 12-year-old girl living in Dire Dawa described her experience:

I finished school in the middle of grade 4. Students were calling us 'Somali' and the teacher was also not stopping students when they were insulting us. The students had a meeting and were talking about killing Somali students. 
Then I stopped attending school. Students also throw stones at us. It was the teachers who advised students to beat us and insult us. When we were not going to school, teachers came and asked us to go back to school. But they didn't stop students who were insulting us. The students also chased us out.

Other internally displaced adolescents emphasised that it was not just in schools but also in the wider community where they were at risk of violence from host community members. As a 15-year-old girl explained:

We are not accepted here. The community does not want to see us... 'We do not need Hararghe people'. One day what did they say? The ration came too late.... We did not have anything to eat. Men woke up in the morning and said 'let us go for peaceful demonstration since we do not have anything to eat'. We went to the asphalt for a demonstration. The whole community beat us with sticks. Some of our people were injured and bleeding. Then after, they started to say, 'May the Lord remove people of Hararghe from here'.

In the camp for internally displaced people in Dire Dawa, conflict between rival clans was an additional source of stress for young people. Given the camp's poor conditions and very limited resources, clan rivalries quickly surfaced, and some adolescents reported feeling stressed and unsafe, fearing both the host community and others in the camp.

\section{Support services}

Despite having experienced severe trauma, many respondents reported that no formal psychosocial support was provided by the government, NGOs or religious institutions. As one man in an FGD for internally displaced adults in Fedis district explained:

We and our children were traumatised when we came here. What can we do? We are displaced people. My child became like he was insane.... When he remembers, he starts to run... . There is no psychosocial support. What can we do? Our life is one of poverty.... One of my children left and moved away alone.... We [IDPs] are separated from our families.... We are dispersed in various areas where we do not know each other.... We trust in God but we did not make any other effort to support the children to be free from these problems.

Similarly, an 18-year-old girl living in Batu noted:

We do not talk to the Women's Affairs office. We do not know them. . . No one talks to us. We are dependent on [other] displaced families. 
In Fedis district, respondents in an FGD noted that compared to relatives in neighbouring districts, they felt poorly supported by the district authorities and only received support after complaining vociferously. A participant in an FGD for mothers emphasised:

We were stressed very much [when we were displaced] and we have been hoping that the government provides us [with] support. Fedis district is leaving us in a problem. Displaced people in other districts like Babile are getting good support, [and] they are changed.... Last time they gave us food support after a delay of three months. They gave us food when we were about to decide to go back to Somali and die there. The district reports that it has no displaced people and that everyone has already been resettled. They only gave us support after we went to the office and complained loudly.

In Batu, internally displaced adolescents reported that even though the food insecurity situation was becoming intolerable, when they complained as a group, they were beaten by police and now feel despair that they have no avenue to air grievances or seek redress. As an 18-year-old girl noted:

We stopped complaining since we were beaten. No one gives us solution. We stopped it, losing hope. When we request it, we are beaten and come back to our home. One day the rations stopped and we became hungry. When we requested ... food support, they told us they do not have any. ... So we were beaten by police, adults together with their children. There is a child who died because he was beaten after that request.

\section{Discussion and implications for policy}

Our findings show that internally displaced adolescents in Ethiopia face multiple and intersecting forms of disadvantage. These include age, gender and their experience as citizens outside of communities, lacking a sense of belonging. Yet what can also be noted in analysing these findings are distinctions between geographical residence (for example being in remote rural host communities or urban makeshift camps) which shape available livelihood options and experiences of stigma and discrimination.

In terms of economic vulnerabilities, our findings highlight that internally displaced adolescents face significant age-related disadvantages, including limited access to education (partly due to lack of certificates allowing them to enter the appropriate grade-for-age) and exposure to child labour (among younger adolescents) to support household needs. Older adolescents also face a dearth of decent employment opportunities due to limited education and discrimination by host communities barring them from taking up local job opportunities. For older adolescents living apart from their families, the lack of adolescent-responsive social 
protection measures forced them into highly precarious daily struggles to meet basic needs, with many facing chronic food insecurity.

The patterning of this disadvantage was significantly shaped by geography, with young people in remote rural host communities in East Hararghe facing exploitative agricultural work, while their peers in urban host communities and camps faced unemployment and indebtedness. While gender norms typically shape livelihood opportunities for young people in Ethiopia (see Jones, Baird et al., 2019; Jones, Baird, Hicks, Presler-Marshall et al., 2018), the extreme poverty faced by internally displaced adolescents in our sample meant that such differences did not emerge; adolescent girls and boys both took on whatever scarce work was available.

In terms of psychosocial vulnerabilities, our findings also point to marked ageand gender-specific challenges, including serious mental trauma and persistent mental ill health as a result of experiencing and witnessing violence during conflict and displacement. Adolescent boys' accounts of the conflict were shaped by extreme physical violence, while adolescent girls also spoke of sexual and genderbased violence, the effects of which drive their emphasis on finding safe spaces in host communities and camps. In terms of interactions with family, adolescent girls and boys both underscored that they sought to protect their parents from the full extent of their stress and suffering during displacement, mindful that their parents are also coping with high levels of stress. At the community level, while GAGE research with non-displaced adolescents in the same communities found significant differences in young people's exposure to peer violence (with boys at greater risk of bullying and girls at greater risk of sexual violence) (Jones, Presler-Marshall et al., 2019), our research with displaced adolescents (girls and boys) underscored their high exposure to verbal and physical violence from peers, pointing to high levels of community discrimination and stigma towards displaced persons. Finally, all adolescents - irrespective of age, gender or geographical location - emphasised that they had no access to psychosocial support services.

Internally displaced adolescents have a dearth of champions to advocate for interventions to address their vulnerabilities, at both the national and international levels. This places them at significant risk of being 'left behind'. For Ethiopia, ratifying the Kampala Convention was an important starting point in addressing the specific vulnerabilities facing IDPs. Yet there is an urgent need for more sustained support, so that internally displaced adolescents can build meaningful lives and aspire to better futures. When there is limited attention to IDPs in general, young people and their age- and gender-specific needs are especially likely to be overlooked. Though the Ministry of Peace is mandated to oversee the resettlement of those displaced in 2018, it has not been tasked with monitoring and providing assistance in their resettled localities - leading to a lack of knowledge about how young people have been affected. The 2019 Humanitarian Response Plan still pays inadequate attention to the impact of displacement on adolescents and young people, who must cope with displacement during one of the most challenging life stages. 
Resettlement in host communities is an important first step, but many IDPs will need social assistance for a prolonged period of time, given their dearth of assets, savings and education. Age- and gender-responsive social protection that provides an integrated package of support alongside complementary services such as catchup classes and psychosocial support is critical for internally displaced adolescents if they are not to be 'left behind'. These strategies must also acknowledge the different vulnerabilities of and support needed by IDPs, especially between camp and urban settings, given that our findings suggest they have experienced varying degrees and types of discrimination and stigma.

More work is also needed to raise awareness with actors mandated to support young people and IDPs. The SDGs include no indicators on internal displacement, despite recognising IDPs as a particularly marginalised group. More specific monitoring and indicators at all levels would generate better information on how to support internally displaced adolescents. Coordinated action and champions - internationally and nationally - are also vital for advocating for internally displaced adolescents and for holding states and international actors to account. There is a clear need for NGOs to fill some of these gaps and for a Special UN Rapporteur to be dedicated to the impact of internal displacement on children and adolescents. These measures together will enable a better understanding not only of how to target support to the most vulnerable internally displaced adolescents but also of their longer-term development trajectories, as well as enabling actors to identify which forms of support are most critical at which junctures.

\section{Conclusion}

National and international agencies responding to internal displacement have begun to mainstream age and gender into their working practices, but there has been little research to date to understand how internal displacement impacts young people in particular or to identify how existing support mechanisms can be strengthened and adapted to address adolescents' needs. This chapter has emphasised the intersecting vulnerabilities of internally displaced adolescents in Ethiopia, focusing on economic and psychosocial vulnerabilities. Poor psychosocial outcomes were linked to economic deprivation, violence and threats to bodily integrity - which manifested in different ways on the basis of age and gender - as well as to strained social cohesion, both within camps and host communities.

While internally displaced adolescents reported a number of negative experiences at the individual and community levels, continued inaction at the national and international levels will continue to exacerbate age and gender vulnerabilities, especially in the context of highly impoverished host communities who are simultaneously vulnerable to recurrent climatic shocks. Addressing these failures requires a deeper understanding of young people's experiences, to which this chapter has sought to contribute. The next step is to hold stakeholders accountable for delivering more sustained and coordinated support for internally displaced adolescents 
beyond an initial emergency phase, including age- and gender-responsive social protection programming, to ensure that they are not 'left behind'.

\section{Note}

1 Dire Dawa city is renowned for its ethnic pluralism, with formal power sharing between Oromos, Somalis and other ethnic groups. Hence it can provide a possible explanation as to why some Somalis sought refuge here (rather than in Somali region), especially if they had family or relatives in Dire Dawa, and given better employment prospects in a large urban centre rather than the rural areas of Somali region.

\section{References}

Afifi, T., Govil, R., Sakdapolrak, P., and Warner, K. (2012) Climate change, vulnerability and human mobility: perspectives of refugees from the East and Horn of Africa. Report No. 1. Tokyo, Japan: United Nations University Institute for Environment and Human Security.

Araya, M., Chotai, J., Komproe, I. H., and de Jong, J. T.V. M. (2007) Gender differences in traumatic life events, coping strategies, perceived social support and sociodemographics among postconflict displaced persons in Ethiopia. Social Psychiatry and Psychiatric Epidemiology 42: 307-315.

Betancourt, T., and Khan, K. (2008) The mental health of children affected by armed conflict: protective processes and pathways to resilience. International Review of Psychiatry 20: 317-328.

Brookings-LSE. (2014) Improving the protection of internally displaced women: assessment of progress and challenges. Washington, DC: Brookings Institution.

Buscher, D., and Makinson, C. (2006) Protection of IDP women, children and youth. Forced Migration Review (Special issue: Putting IDPs on the map: achievements and challenges): 15-16.

Cazabat, C. (2019) Sex matters: a gender perspective on internal displacement. Briefing paper. Geneva: Internal Displacement Monitoring Centre.

Clark-Kazak, C. (2009) Representing refugees in the life cycle: a social age analysis of United Nations High Commissioner for Refugees annual reports and appeals 1999-2008. Journal of Refugee Studies 22(3): 302-322.

Collins, P. (1990) Black feminist thought: knowledge, consciousness, and the politics of empowerment. New York: Routledge.

Cotroneo, A. (2018) Strengthening implementation of the Guiding Principles by affected states. Forced Migration Review 59: 29-31.

Crenshaw, K. (1989) Demarginalizing the intersection of race and sex: a black feminist critique of antidiscrimination doctrine, feminist theory and antiracist politics. University of Chicago Legal Forum 1: 139-168.

de Barre, A., Henry, A., and Rahmaty, M. (2018) Reaching internally displaced persons to achieve the 2030 Agenda. Oslo: International Peace Institute. Available at: https://reliefweb.int/ sites/reliefweb.int/files/resources/1811_IDPs-and-SDGs.pdf

de Brauw, A., and Mueller, V. (2012) Do limitations in land rights transferability influence mobility rates in Ethiopia? Journal of African Economies 21(4): 548-579.

Del Franco, N. (2012) Negotiating adolescence in rural Bangladesh: a journey through school, love and marriage. New Delhi: Zubaan Books.

Evans, R., Lo Forte, C., and McAslan Fraser, E. (2013) UNHCR's engagement with displaced youth: a global review. Geneva: UNHCR Policy Development and Evaluation Service. 
GAGE consortium. (2019) Gender and adolescence: why understanding adolescent capabilities, change strategies and contexts matters. Second edition. London: Gender and Adolescence: Global Evidence (GAGE).

Government of Ethiopia. (2019) Ethiopia humanitarian response plan. Addis Ababa: OCHA and National Disaster Reduction Management Commission. Available at: www. humanitarianresponse.info/sites/www.humanitarianresponse.info/files/2019/03/2019_ HRP_030719.pdf (Accessed 6 August 2020).

Guerrero, A. L., and Tinkler, T. (2010) Refugee and displaced youth negotiating imagined and lived identities in a photography-based educational project in the United States and Colombia. Anthropological Education Quarterly 41:11-19.

Habte, B., and Kweon,Y. J. (2018) Addressing internal displacement in Ethiopia. Forced Migration Review 59: 40-42.

Internal Displacement Monitoring Centre (IDMC). (2018) Ethiopia. Available at: www. internal-displacement.org/countries/ethiopia (Accessed 6 August 2020).

Internal Displacement Monitoring Centre (IDMC). (2020) Number of IDPs by age at the end of 2019. Briefing paper. Internal Displacement Monitoring Centre. Available at: www. internal-displacement.org/sites/default/files/publications/documents/202004-agedisaggregated-IDP-data-paper.pdf (Accessed 17 June 2020).

International Organization for Migration (IOM). (2017) Report on IDP verification assessment in East Hararghe zone of Oromia region and Dire Dawa town. Geneva: IOM. Available at: www.humanitarianresponse.info/sites/www.humanitarianresponse.info/files/2018/12/ ETH-IOM-East-Hararge-Oromia-IDP-Verification-Assessment-20171007.pdf (Accessed 6 August 2020).

International Organization for Migration (IOM). (2019) Ethiopia national displacement report: round 18. Geneva: IOM. Available at: https://displacement.iom.int/reports/ethiopia--national-displacement-report-1-june---july-2019?close=true (Accessed 16 July 2020).

Jebena, M., Lindstrom, D., Belachew, T., Hadley, C., Lachat, C., Verstaeten, R., De Cock, N., and Kolsteren, P. (2016) Food insecurity and common mental disorders among ethiopian youth: structural equation modeling. PLoS ONE 11(11): e0165931.

Jones, N., Baird, S., Hicks, J., Devonald, M., Neumeister, E., Presler-Marshall, E., Iyasu, A., and Yadete, W. (2019) Adolescent economic empowerment in Ethiopia. London: Gender and Adolescence: Global Evidence.

Jones, N., Baird, S., Hicks, J., Presler-Marshall, E., Woldehanna, T., and Yadete, W. (2018) Adolescent well-being in Ethiopia: exploring gendered capabilities, contexts and change strategies. Synthesis report on GAGE Ethiopia baseline findings. London: Gender and Adolescence: Global Evidence.

Jones, N., Pincock, K., Baird, S., Yadete, W., and Hamory Hicks, J. (2020) Intersecting inequalities, gender and adolescent health in Ethiopia. International Journal for Equity in Health 19: 97. https://doi.org/10.1186/s12939-020-01214-3

Jones, N., Presler-Marshall, E., Baird, S., Hicks, J., Emirie, G., Yadete, W., Alemayehu, Y., Bekele, B., and Kifle, E. (2019) Adolescent bodily integrity and freedom from violence in Ethiopia. A report on GAGE Ethiopia baseline findings. London: Gender and Adolescence: Global Evidence.

Kreichauf, L. (2018) From forced migration to forced arrival: the campization of refugee accommodation in European cities. Comparative Migration Studies 6(1).

Landau, L. (2014) Refugees and IDPs. In: Fiddian-Qasmiyeh, E., Loescher, G., Long, K., and Sigona, N. (Eds.), Oxford handbook of refugee and forced migration studies. Oxford: Oxford University Press. 
Lanz, D. (2008) Subversion or reinvention? Dilemmas and debates in the context of UNHCR's increasing involvement with IDPs. Journal of Refugee Studies 21(2): 192-209.

Murphy, M., Jones, N., Yadete, W., and Baird, S. (2020) Gender-norms, violence and adolescence: exploring how gender norms are associated with experiences of childhood violence among young adolescents in Ethiopia. Global Public Health. DOI: 10.1080/174 41692.2020.1801788

Nahmias, P., and Krynsky Baal, N. (2019) Including forced displacement in the SDGs: a new refugee indicator. UNHCR Blog, December 2019. Available at: www.unhcr.org/ blogs/including-forced-displacement-in-the-sdgs-a-new-refugee-indicator (Accessed 4 August 2020).

Nash, J. C. (2017) Intersectionality and its discontents. American Quarterly 69(1): 117-129.

OCHA. (1998) Guiding principles on internal displacement. Available at: www.unocha.org/ sites/dms/Documents/GuidingPrinciplesDispl.pdf (Accessed 15 June 2020).

OCHA. (2019a) Ethiopia: IDP situation report. Available at: https://reliefweb.int/report/ ethiopia/ethiopia-idp-situation-report-may-2019 (Accessed 9 June 2020).

OCHA. (2019b) Ethiopia: immediate humanitarian funding priorities 1st April - 30th June 2019. Prioritisation statement, 29 March 2019. UN Office for the Coordination of Humanitarian Affairs.

Punch, S. (2002) Youth transitions and interdependent adult - child relations in rural Bolivia. Journal of Rural Studies 18(2): 123-133.

Sen, A. K. (1984) Commodities and capabilities. Oxford: Oxford University Press.

Sen, A. K. (2004) Capabilities, lists, and public reason: continuing the conversation. Feminist Economics 10(3): 77-80.

Sida. (2019) Ethiopia: humanitarian crisis analysis 2019. Swedish International Development Cooperation Agency. Available at: www.sida.se/globalassets/sida/eng/how-we-work/ humanitarian-aid/hca-2019/hca-ethiopia-2019.pdf

Siriwardhana, C., and Stewart, R. (2013) Forced migration and mental health: prolonged internal displacement, return migration and resilience. International Health 5(1): 19-23.

Turk, V. (2018) The promise and potential of the global compact on refugees. International Journal of Refugee Law 30(4): 575-583.

UNICEF. (2020) Lost at home: the risks and challenges for internally displaced children and the urgent actions needed to protect them. Geneva: UNICEF. Available at: https://data.unicef. org/resources/lost-at-home-risks-faced-by-internally-displaced-children/ (Accessed 6 August 2020).

United Nations. (2015) Transforming our world: the 2030 Agenda for Sustainable Development. New York: United Nations. Available at: https://sustainabledevelopment.un.org/ post2015/transformingourworld/publication

United Nations High Commissioner for Refugees (UNHCR). (2018) UNHCR policy on age, gender and diversity. UNHCR. Available at: www.unhcr.org/5aa13c0c7.pdf

Yigzaw, G. S., and Abitew, E. B. (2019) Causes and impacts of internal displacement in Ethiopia. African Journal of Social Work 9(2): 32-41.

Yuval-Davis, N. (2006) Intersectionality and feminist politics. European Journal of Women's Studies 13(3): 193-209. 